\title{
Pengaruh Kualitas Pelayanan dan Kepuasan Konsumen terhadap Loyalitas Konsumen CV. Saga Selaras Pratama
}

\author{
Hilda Yunita Wono ${ }^{1 *}$, Michelle Angela ${ }^{2}$, dan Michael Ivan Reinal ${ }^{3}$ \\ 1,2,3,Universitas Ciputra Surabaya \\ Email: Hilda.yunita@ciputra.ac.id ${ }^{1 *}$, michelleangela97@ymail.com², mivan01@student.ciputra.ac.id ${ }^{3}$ \\ *corresponding author
}

Keywords:

Service Quality, Consumer Satisfaction, Consumer Loyalty

\begin{abstract}
The process of consumption is closely related to the relationship between consumers and companies providing goods or services. One of the important things in this relationship is customer loyalty which is influenced by several factors, including service quality seen from five main dimensions and customer satisfaction which also has four indicators to be seen. These two factors are the object of research due to the high case of complaints against the subject of this study, CV Saga Selaras Pratama. This store is a simple shop that does not have branches and is engaged in the wholesale and retail sales of household appliances, stationery, and children's toys that were established in 2014 and are located in Malang. This study wants to find out whether there is an influence of service quality and customer satisfaction which is on consumer loyalty. This research uses a quantitative descriptive method by collecting data using a questionnaire. The population of this study is unknown due to limited data possessed by CV Saga Selaras Pratama in collecting data of customers who have done shopping there. Therefore, for the study sample using a nonprobability method with an accidental sampling method with an error level of $10 \%$. The number of data samples used was 272 respondents. This research is new because the existing research all use research subjects which are stores with well-known brands such as McDonald's, hotels and famous restaurants. The results of this study, found that service quality has a positive effect on customer loyalty of 0.265 and customer satisfaction also has a positive effect on customer loyalty of 0.349. The conclusion of this study shows that service quality and customer satisfaction have a positive effect on customer loyalty with numbers that are not too high. This is because buyers who come repeatedly still come not the main because of the quality of service and satisfaction, but there are other factors that make them keep returning to shop at CV Saga Selaras Pratama.
\end{abstract}

\begin{abstract}
ABSTRAK
Proses konsumsi erat kaitannya dengan hubungan antara konsumen dan perusahaan penyedia barang atau jasa. Salah satu hal penting dalam hubungan tersebut adalah loyalitas pelanggan yang dipengaruhi beberapa faktor, antara lain kualitas pelayanan yang dilihat dari lima dimensi utama dan kepuasan konsumen yang juga memiliki empat indikator yang akan dilihat. Kedua faktor inilah yang menjadi objek dalam penelitian karena adanya kasus tinggi keluhan terhadap subyek penelitian ini yaitu CV Saga Selaras Pratama. Toko ini merupakan toko sederhana yang belum mempunyai cabang dan bergerak dalam bidang penjualan grosir maupun eceran peralatan rumah tangga, alat tulis, dan mainan anak yang berdiri pada 2014 dan berlokasi di Kota Malang. Penelitian ini ingin mengetahui apakah terdapat pengaruh dari kualitas pelayanan dan kepuasan pelanggan yang merupakan terhadap loyalitas konsumen. Penelitian ini menggunakan metode deskriptif kuantitatif dengan
\end{abstract}


pengumpulan data menggunakan kuesioner. Populasi dari penelitian ini tidak diketahui karena keterbatasan data yang dimiliki CV Saga Selaras Pratama dalam mengumpulkan data pelanggan yang pernah melakukan kegiatan belanja disana. Oleh karena itu, untuk sampel penelitian menggunakan metode non-probabilitas dengan metode sampling aksidental dengan taraf kesalahan sebesar 10\%. Jumlah sampel data yang digunakan sebesar 272 responden. Penelitian ini baru karena dari penelitian yang sudah ada semuanya menggunakan subjek penelitian yang merupakan toko dengan brand ternama seperti McDonald's, hotel, serta rumah makan terkenal. Hasil penelitian ini, ditemukan bahwa kualitas pelayanan berpengaruh positif terhadap loyalitas pelanggan sebesar 0,265 dan kepuasan konsumen berpengaruh positif pula terhadap loyalitas pelanggan sebesar 0,349. Kesimpulan penelitian ini menunjukkan bahwa kualitas pelayanan dan kepuasan konsumen berpengaruh secara positif terhadap loyalitas konsumen dengan angka yang tidak terlalu tinggi. Hal ini dikarenakan pembeli yang datang berulang tetap saja datang bukan utama karena kualitas pelayanan serta kepuasan, namun ada faktor lain yang membuat mereka tetap kembali berbelanja di CV Saga Selaras Pratama.

Copyright (C) 2020 Channel Jurnal Komunikasi. All right reserved.

\section{PENDAHULUAN}

Kegiatan usaha adalah suatu aktivitas yang dilakukan dalam upaya mendapat keuntungan sekaligus memenuhi kebutuhan yang diperlukan oleh pasar. Kegiatan usaha terus berkembang sejalan dengan berkembangnya populasi masyarakat yang semakin besar. Hal ini ditunjukkan dengan jumlah perusahaan baru yang mencapai 3,98 juta dalam kurun waktu sepuluh tahun terakhir (Agustinus, 2017). Dalam menjalankan kegiatan usaha, konsumen merupakan salah satu unsur yang utama yang turut menentukan suatu bisnis dapat beroperasi lebih lanjut atau tidak. Pentingnya konsumen bagi kegiatan usaha memerlukan perhatian dari perusahaan sebagai penyelenggara kegiatan usaha, terutama mengenai pertimbangan konsumen dalam memilih.

Menurut Kasmir (2011), terdapat beberapa faktor yang mengakibatkan konsumen meninggalkan perusahaan. Faktor tersebut berupa harga yang tidak kompetitif, tidak memuaskannya pelayanan, produk yang berkualitas kurang baik, produk yang tidak lengkap, janji promosi yang tidak ditepati, tidak tepat waktu, serta lokasi yang sulit dijangkau. Untuk mencegah hal itu diperlukan konsep pemasaran yang mengutamakan konsumen. Haryono (2013) menyampaikan, bahwa sikap, pengetahuan produk, serta keterampilan melayani sangat diperlukan. Apabila dipahami lebih lanjut, dapat dinilai sebagai kualitas pelayanan apabila dilihat dari beberapa aspek. Aspek tersebut terdiri dari kemudahan dalam melayani, kecepatan merespons permintaan konsumen, kemampuan mengenali produk, serta keramahan dalam bersikap dan bertindak ketika menghadapi konsumen.

Pelayanan sendiri, menurut Kasmir (2011), merupakan suatu tindakan atau aktivitas yang dilakukan dengan tujuan menciptakan perasaan puas dari konsumen. Tindakan tersebut berguna untuk meningkatkan loyalitas konsumen pada perusahaan. Secara tidak langsung, loyalitas konsumen ini mampu meningkatkan penjualan yang dilakukan oleh perusahaan dan mendorong peningkatan keuntungan perusahaan. Ditambahkan oleh Almana, Sudarmanto, \& Ismail (2018), loyalitas pelanggan merupakan perilaku yang ditunjukkan melalui pembelian yang dilakukan secara rutin dan didasarkan pada unit pengambilan keputusan. Selanjutnya menurut Lovelock, Wirtz, Mussry (2011), loyalitas pelanggan memungkinkan pelanggan untuk merekomendasikan perusahaan tersebut atau cenderung setia.

Penelitian terdahulu yang telah dilakukan oleh Feibe Permatasari Karundeng(2013), Selvy Normasari (2013) dan Inka Janita Sembiring (2014), semuanya menggunakan subjek penelitian tempat-tempat ternama seperti McDonald's, rumah makan dan juga hotel untuk melihat pengaruh pentingnya kualitas pelayanan, kepuasan pelanggan serta loyalitas pelanggan dalam sebuah usaha. Penelitian ini ingin melakukan sesuatu yang berbeda dengan subjek penelitian di CV Saga Selaras Pratama merupakan sebuah toko yang menjual produk secara eceran maupun grosir termurah di Kota Malang. CV Saga Selaras Pratama bergerak di bidang dagang yang menjual berbagai jenis barang dimulai dari alat tulis seperti buku tulis, bolpoin, set alat tulis, mainan anak seperti mobil-mobilan, robot, boneka, mainan edukasi hingga peralatan rumah tangga seperti alat masak, ember, sapu dan masih banyak lagi. CV Saga Selaras Pratama pertama kali berdiri pada 24 Mei 2004 dan berlokasi di Jl. Zainul Arifin No. 90, Kota Malang. Dalam mendirikan usaha ini, CV Saga Selaras Pratama berusaha memenuhi kepuasan konsumen, dimulai dari faktor harga yang murah, kelengkapan produk yang menjual berbagai varian produk, kenyamanan produk dimana masing-masing rak di tata sedemikian rupa sehingga memudahkan pembeli dalam menemukan produk yang dibutuhkan maupun kemudahan selama berbelanja di CV Saga Selaras Pratama 
dimana disediakan penitipan barang, keranjang belanja serta pegawai yang dapat membantu pelanggan untuk meletakkan barang belanjaan mereka di kasir.

Oleh karena ragam produk yang sangat bervariasi serta peminatnya yang sangat banyak, persaingan dalam industri ini sangatlah ketat karena produk yang CV Saga Selaras Pratama merupakan produk yang umum dalam kehidupan seharihari dan mudah ditemukan oleh masyarakat. Hal ini sangat penting dan menjadi perhatian bagi CV Saga Selaras Pratama untuk mempertahankan pelanggannya berdasarkan Google review mengenai CV Saga Selaras Pratama yang hasilnya dapat dilihat pada tabel 1.1 dimana masih terdapat beberapa keluhan pelanggan terhadap CV Saga Selaras Pratama.

Tabel 1.1 Pendapat Pelanggan tentang CV Saga Selaras Pratama

\begin{tabular}{|l|}
\hline Untuk karyawannya ada yang ramah ada pula yang kurang ramah \\
\hline Pelayanannya perlu diperbaiki karena pegawainya judes \\
\hline $\begin{array}{l}\text { Masalahnya ada pada pegawai yang pakai hijab dan membaca terus dan cuek, ditanya tidak ramah, wajah } \\
\text { cemberut. Di minta ambil barang malah bicara soal harga, benar-benar tidak sopan }\end{array}$ \\
\hline Pegawai yang bungkus kado jutek banget, sok. Sombong banget, mohon diperbaiki \\
\hline $\begin{array}{l}\text { Pelayanan beberapa karyawan kurang ramah, terutama kasir. Pernah beli disini tanpa diberi struk, ditanya } \\
\text { bilang nggak ada. Padahal jelas-jelas mesin kasirnya mengeluarkan struk dan juga kasirnya pelit kantong } \\
\text { kresek. Harap diperbaiki lagi pelayanannya }\end{array}$ \\
\hline Pegawai kasirnya judes \\
\hline
\end{tabular}

Sumber: Diolah Penulis, 2019

Berdasarkan tabel 1.1 di atas, data tersebut menunjukkan bahwa menurut pelanggan kualitas pelayanan merupakan salah satu faktor terpenting bagi pelanggan. Dari tabel tersebut dapat dilihat bahwa pelanggan merasa kurang puas dengan kualitas pelayanan yang diberikan oleh CV Saga Selaras Pratama dan pelanggan memiliki banyak keluhan terkait kualitas pelayanan yang diberikan oleh CV Saga Selaras Pratama, terutama dari bagaimana karyawan merespon pelanggan. Berdasarkan hasil didapat dari Google review dari CV Saga Selaras Pratama juga didapatkan data bahwa rating kepuasan pelanggan di CV Saga Selaras Pratama sebesar 3,9/5 yang didapat dari 108 review pelanggan yang menandakan bahwa kepuasan pelanggan terhadap CV Saga Selaras Pratama masih belum terlalu baik. Sehingga berdasarkan latar belakang masalah yang ada, maka dilakukan penelitian untuk melihat Pengaruh Kualitas Pelayanan dan Kepuasan Pelanggan Terhadap Loyalitas Pelanggan CV Saga Selaras Pratama.

\section{TINJAUAN PUSTAKA}

\section{A. Kualitas Pelayanan}

Kualitas pelayanan merupakan suatu upaya yang dilakukan untuk menciptakan kepuasan kepada konsumen. Upaya tersebut berupa bagaimana cara perusahaan secara langsung dalam melayani konsumen. Konsep kualitas pelayanan disimpulkan oleh Putri (2017) sebagai suatu penyajian jasa maupun produk sesuai dengan standar perusahaan. Penyampaian jasa maupun produk diupayakan sama dengan harapan konsumen atau melebihi harapannya. Untuk mengukur suatu kualitas pelayanan, terdapat sepuluh dimensi yang bisa diukur kemudian disederhanakan menjadi lima dimensi sesuai dengan yang digunakan oleh Fatona (2010) yang menjadi indikator pengukuran dalam penelitian ini. Lima dimensi tersebut terdiri dari:

1. Produk-produk fisik atau tangibles

Produk fisik merupakan sarana yang digunakan untuk mewujudkan pelayanan secara langsung yang merupakan syarat dalam suatu transaksi barang dan jasa.

2. Keandalan atau reliability

Keandalan merupakan kemampuan dalam melayani konsumen yang dijanjikan dengan 3 indikator yaitu tepat atau accurately, dapat dipercaya atau dependability dan yang terakhir adalah tepat waktu atau on time dan tanpa ada kesalahan.

3. Daya tanggap atau responsiveness

Daya tanggap merupakan kesadaran bagi karyawan untuk mau atau ingin dalam membantu serta memberikan sesuai kebutuhan konsumen.

4. Jaminan atau assurance

Jaminan terdiri dari 5 unsur yaitu pengetahuan, kemampuan, keramahan, kesopanan dan yang terakhir dapat dipercaya.

5. Empati atau emphaty

Empati merupakan sikap karyawan maupun perusahaan untuk memahami kebutuhan atau kesulitan yang dialami oleh konsumen. 


\section{B. Kepuasan Konsumen}

Kepuasan atau satisfaction, seperti yang dijelaskan oleh Kotler \& Keller (2009), adalah suatu perasaan yang dialami seseorang yang muncul akibat membandingkan hasil yang diekspektasikan dengan hasil yang diperoleh secara nyata. Terdapat dua jenis kepuasan konsumen yang dirasakan setelah melakukan transaksi, yaitu kepuasan fungsional dan kepuasan psikologikal. Menurut Kaihatu, Daengs, \& Indrianto (2015), kepuasan fungsional merupakan kepuasan yang dirasakan apabila produk sesuai dengan fungsi yang diharapkan. Sedangkan kepuasan psikologikal dirasakan ketika suatu atribut tidak memiliki wujud atau bersifat intangible, namun dapat memberikan perasaan puas.

Kepuasan konsumen ini dapat diukur sehingga perusahaan mampu melihat tingkat kepuasan konsumen mereka dan juga menyusun strategi dalam upaya menciptakan kepuasan konsumen. Menurut Tjiptono dan Diana (2015), terdapat empat indikator yang dapat dinilai, yaitu niat melakukan repurchase, loyalitas konsumen, perilaku menyampaikan keluhan, serta gethok tular positif yang merekomendasikan hal positif mengenai perusahaan.

\section{Loyalitas Konsumen}

Loyalitas suatu perusahaan yang disampaikan Aryani dan Rosinta (2010) secara gamblang dinyatakan sangat dipengaruhi cara perusahaan dalam usaha memuaskan konsumen. Selanjutnya, loyalitas konsumen yang disampaikan oleh Shandy Widjoyo Putro dkk (2014) merupakan hal sangat penting bagi perusahaan yang bergerak di bidang jasa maupun produk untuk meningkatkan keuntungan bagi perusahaan. Apabila konsumen tidak loyal terhadap jasa maupun produk suatu perusahaan, maka konsumen akan berpaling ke produk lain. Salah satu cara untuk mempertahankan loyalitas konsumen tentunya dengan memberikan pelayanan yang baik dan diharapkan dapat membuat konsumen untuk kembali melakukan transaksi. Loyalitas ini merupakan kunci keberhasilan dari pemasaran jangka panjang dan menjaga pendapatan perusahaan agar tetap stabil. Terdapat empat hal yang digunakan untuk mengukur loyalitas konsumen, yaitu percaya pada pilihan pribadi, tingkat pembelian lebih tinggi, loyal terhadap perusahaan, dan loyal terhadap merek.

\section{METODE PENELITIAN}

Penelitian ini merupakan penelitian deskriptif dengan metode kuantitatif. Dalam penelitian ini, yang menjadi populasi yaitu pelanggan CV Saga Selaras Pratama yang telah berbelanja di toko tersebut. Jumlah pasti populasi penelitian ini tidak diketahui dikarenakan tidak tersedianya data yang pasti dari total pelanggan CV Saga Selaras Pratama. Sedangkan untuk sampel penelitian berjumlah 272 responden. Metode yang digunakan untuk menentukan sampel adalah non-probabilitas dengan metode aksidental. Untuk pengumpulan data, penelitian ini menggunakan kuesioner sebagai sumber data primer dengan pertanyaan tertutup dan model respon skala likert.

Data yang terkumpul dianalisis menggunakan metode Regresi Linier Berganda untuk mengetahui korelasi variabel independen dan dependen. Metode Regresi Linier Berganda menurut Syofian Siregar (2015) ini di proses dengan rumus sebagai berikut:

$$
\begin{aligned}
& Y=\alpha+\beta_{1} X_{1}+\beta_{2} X_{2}+e \\
& \text { Dimana: } \\
& Y=\text { Loyalitas Pelanggan } \\
& \alpha=\text { Konstanta } \\
& \beta_{1}, \beta_{2}=\text { Koefisien Regresi } \\
& X_{1}=\text { Kualitas Layanan } \\
& X_{2}=\text { Kepuasan Pelanggan } \\
& e=\text { Kesalahan Prediksi (error) }
\end{aligned}
$$

Untuk mengetahui pengaruh variabel independen terhadap variabel dependen secara simultan, maka dilakukan Uji F. Sedangkan untuk mengetahui pengaruh secara parsial digunakan Uji T untuk mengetahui pengaruhnya. Derajat signifikansi Uji T dan Uji yaitu sebesar 0,05.

\section{A. Temuan Data}

Dari hasil pengolahan data berikut untuk variabel $X_{1}$ yang mewakili variabel kualitas pelayanan, ditemukan bahwa pada variabel $X_{1.10}$ mengenai kemampuan pegawai CV Saga Selaras Pratama dalam pemberian kepercayaan menunjukkan nilai rata-rata sebesar 3,52 . 
Tabel 3.1 Deskriptif Statistik Variabel Kualitas Pelayanan

\begin{tabular}{cc|c|c|c|c} 
& $\mathrm{N}$ & Minimum & Maximum & Mean & Std. Deviation \\
\hline $\mathrm{x} 1.1$ & 272 & 1 & 5 & 3,73 &, 945 \\
\hline $\mathrm{x} 1.2$ & 272 & 1 & 5 & 3,71 &, 995 \\
\hline $\mathrm{x} 1.3$ & 272 & 1 & 5 & 3,81 &, 919 \\
\hline $\mathrm{x} 1.4$ & 272 & 1 & 5 & 3,68 &, 997 \\
\hline $\mathrm{x} 1.5$ & 272 & 1 & 5 & 3,99 & 1,049 \\
\hline $\mathrm{x} 1.6$ & 272 & 1 & 5 & 3,72 & 1,107 \\
\hline $\mathrm{x} 1.7$ & 272 & 1 & 5 & 3,60 & 1,174 \\
\hline $\mathrm{x} 1.8$ & 272 & 1 & 5 & 3,59 & 1,100 \\
\hline $\mathrm{x} 1.9$ & 272 & 1 & 5 & 3,65 & 1,127 \\
\hline $\mathrm{x} 1.10$ & 272 & 1 & 5 & 3,52 & 1,212 \\
\hline $\mathrm{x} 1.11$ & 272 & 1 & 5 & 3,65 & 1,103 \\
\hline $\mathrm{x} 1.12$ & 272 & 1 & 5 & 3,58 & 1,140 \\
\hline $\mathrm{x} 1.13$ & 272 & 1 & 5 & 3,54 & 1,116 \\
\hline kualitas pelayanan & 272 & 21 & 65 & 47,73 & 9,902 \\
\hline Valid N (listwise) & 272 & & & & \\
\hline
\end{tabular}

Sumber: Diolah Penulis, 2019

Hal ini menunjukkan kualitas pelayan yang diberikan oleh pegawai CV Saga Selaras Pratama masih kurang memuaskan sehingga kepercayaan konsumen menurun. Sementara itu, nilai standar deviasi terendah terjadi pada indikator $\mathrm{X}_{1.3}$, yaitu sebesar 0,920 . Hal ini menunjukkan bahwa respons atas pernyataan tersebut cenderung sama untuk setiap respondennya. Sedangkan untuk indikator lainnya menghasilkan jawaban yang bervariatif.

Untuk variabel kepuasan pelanggan, nilai mean terendah didapat oleh indikator $\mathrm{X}_{2.2}$ mengenai keinginan responden untuk melakukan pembelian ulang. Seperti yang ditunjukan tabel dibawah ini, indikator $\mathrm{X}_{2.2}$ mendapatkan nilai 3.29. Hal ini menunjukkan bahwa keinginan pelanggan dalam melakukan pembelian ulang sangat rendah.

Tabel 3.2 Deskriptif Statistik Variabel Kepuasan Pelanggan

\section{Descriptive Statistics}

\begin{tabular}{l|r|r|r|r|r} 
& N & Minimum & Maximum & Mean & Std. Deviation \\
\hline$\times 2.1$ & 272 & 1 & 5 & 3,63 & 1,129 \\
\hline$\times 2.2$ & 272 & 1 & 5 & 3,29 & 1,193 \\
\hline$\times 2.3$ & 272 & 1 & 5 & 3,56 & 1,051 \\
\hline$\times 2.4$ & 272 & 1 & 5 & 3,63 & 1,119 \\
\hline$\times 2.5$ & 272 & 1 & 5 & 3,53 & 1,113 \\
\hline$\times 2.6$ & 272 & 1 & 5 & 3,61 & 1,200 \\
\hline kepuasan pelanggan & 272 & 6,00 & 30,00 & 21,2463 & 5,54967 \\
\hline Valid N (listwise) & 272 & & & & \\
\hline
\end{tabular}

Sumber: Diolah Penulis, 2019

Sedangkan untuk nilai standar deviasi terendah, indikator $\mathrm{X}_{2.3}$ menunjukkan nilai sebesar 1,051. Untuk indikator lain dalam variabel $\mathrm{X}_{2}$, respons yang didapat cenderung lebih beragam. Nilai mean terendah didapatkan nilai 3,29 pada indikator tidak melakukan pembelian di toko lain. 
Tabel 3.3 Deskriptif Statistik Variabel Loyalitas Pelanggan

\section{Descriptive Statistics}

\begin{tabular}{l|r|r|r|r|r} 
& N & Minimum & Maximum & Mean & Std. Deviation \\
\hline y1 & 272 & 1 & 5 & 3,40 & 1,271 \\
\hline y2 & 272 & 1 & 5 & 3,33 & 1,206 \\
\hline y3 & 272 & 1 & 5 & 3,14 & 1,230 \\
\hline y4 & 272 & 1 & 5 & 3,53 &, 987 \\
\hline y5 & 272 & 1 & 5 & 3,25 & 1,201 \\
\hline y6 & 272 & 1 & 5 & 3,74 &, 991 \\
\hline y7 & 272 & 1 & 5 & 3,68 & 1,015 \\
\hline loyalitas pelanggan & 272 & 7 & 35 & 24,07 & 5,795 \\
\hline Valid N (listwise) & 272 & & & & \\
\hline
\end{tabular}

Sumber: Diolah Penulis, 2019

Untuk variabel Y yang mewakili variabel loyalitas konsumen, butir Y3 menunjukkan nilai 3.14, yang mana pelanggan melakukan pembelian di CV Saga Selaras Pratama untuk kebutuhan sehari-hari. Nilai standar deviasi terendah yaitu 0,985 terdapat pada indikator Y4, sedangkan untuk variabel lain memiliki jawaban yang beragam. berikut:

Dalam penelitian ini, hasil pengolahan data dengan analisis regresi berganda menghasilkan koefisien sebagai

Tabel 3.4 Hasil Uji t

\section{Coefficients $^{\mathrm{a}}$}

\begin{tabular}{|c|c|c|c|c|c|c|}
\hline \multirow[b]{2}{*}{ Mode } & & \multicolumn{2}{|c|}{ Unstandardized Coefficients } & \multirow{2}{*}{$\begin{array}{c}\text { Standardized } \\
\text { Coefficients } \\
\text { Beta }\end{array}$} & \multirow[b]{2}{*}{$\mathrm{t}$} & \multirow[b]{2}{*}{ Sig. } \\
\hline & & $\mathrm{B}$ & Std. Error & & & \\
\hline \multirow[t]{3}{*}{1} & (Constant) & 4,013 & 1,268 & & 3,166 &, 002 \\
\hline & kualitas pelayanan &, 265 &, 032 & 453 & 8,395 &, 000 \\
\hline & kepuasan pelanggan & ,349 & 056 & ,334 & 6,197 &, 000 \\
\hline
\end{tabular}

a. Dependent Variable: Ioyalitas pelanggan

Sumber: Diolah Penulis, 2019

Nilai tersebut dapat disusun menjadi model regresi yang digunakan dalam penelitian ini, yaitu sebagai berikut:

$$
\mathrm{Y}=4,013+0,265 \mathrm{X}_{1}+0,349 \mathrm{X}_{2}
$$

Interpretasi dari koefisien persamaan regresi tersebut dapat dijelaskan sebagai berikut:

1. Konstanta sebesar 4,013 , menyatakan bahwa apabila kualitas pelayanan dan kepuasan pelanggan nilainya 0 maka konstanta loyalitas pelanggan akan tetap sebesar 4,013 .

2. Kualitas pelayanan memiliki nilai koefisien regresi sebesar $+0,265$. Hal ini menunjukkan bahwa setiap kenaikan sebesar satu satuan pada kualitas pelayanan maka nilai loyalitas pelanggan akan meningkat sebesar 0,265 dengan asumsi variabel yang lainnya dianggap konstan.

3. Kepuasan pelanggan memiliki nilai koefisien regresi sebesar $+0,349$. Hal ini menunjukkan bahwa setiap kenaikan sebesar satu satuan maka nilai loyalitas pelanggan akan meningkat sebesar 0,349 dengan asumsi variabel yang lainnya dianggap konstan.

Dari tabel dibawah dapat dilihat bahwa nilai Sig. F Change sebesar $0,000<0,05$ maka variabel $X_{1}$ dan $X_{2}$ berkorelasi dengan variabel Y. 
Tabel 3.4 Analisis Koefisien Korelasi (R) dan Koefisien Determinasi $\left(\mathrm{R}^{2}\right)$

\begin{tabular}{|c|c|c|c|c|c|c|c|c|c|c|}
\hline \multicolumn{11}{|c|}{ Model Summary } \\
\hline \multirow[b]{2}{*}{ Model } & \multirow[b]{2}{*}{$\mathrm{R}$} & \multirow[b]{2}{*}{ R Square } & \multirow[b]{2}{*}{$\begin{array}{l}\text { Adjusted R } \\
\text { Square }\end{array}$} & \multirow[b]{2}{*}{$\begin{array}{l}\text { Std. Error of } \\
\text { the Estimate }\end{array}$} & \multicolumn{5}{|c|}{ Change Statistics } & \multirow[b]{2}{*}{$\begin{array}{l}\text { Durbin- } \\
\text { Watson }\end{array}$} \\
\hline & & & & & $\begin{array}{c}\text { R Square } \\
\text { Change }\end{array}$ & F Change & df1 & $\mathrm{df} 2$ & $\begin{array}{c}\text { Sig. F } \\
\text { Change }\end{array}$ & \\
\hline 1 &, $705^{\mathrm{a}}$ &, 497 &, 494 & 4,123 &, 497 & 133,158 & 2 & 269 &, 000 & 1,927 \\
\hline
\end{tabular}

Sumber: Diolah Penulis, 2019

Tingkat derajat hubungan dalam korelasi variabel $\mathrm{X}_{1}$ dan $\mathrm{X}_{2}$ dengan variabel $\mathrm{Y}$ memiliki tingkat korelasi kuat karena derajat hubungan antara $\mathrm{X}_{1}$ dan $\mathrm{X}_{2}$ dengan variabel $\mathrm{Y}$ sebesar 0,705 dan dalam derajat hubungan nilai Pearson Correlation 0,50 s/d 0,75. Dari tabel tersebut juga diketahui bahwa jumlah persentase total variasi dalam variabel terikat yang diterangkan oleh variabel bebas dalam nilai R Square sebesar 0,497 atau 49,7\%. Hal ini menandakan pengaruh kualitas pelayanan dan kepuasan pelanggan terhadap loyalitas pelanggan adalah sebesar 49,7\% sedangkan sisanya sebesar $50,3 \%$ dijelaskan oleh variabel lain di luar penelitian ini.

\section{HASIL DAN PEMBAHASAN}

Berdasarkan nilai signifikansi pada uji $\mathrm{t}$, dapat disimpulkan bahwa variabel kualitas pelayanan $\left(\mathrm{X}_{1}\right)$ berpengaruh secara signifikan terhadap loyalitas pelanggan CV Saga Selaras Pratama, sehingga hipotesis yang diterima dalam hipotesis pertama bahwa kualitas pelayanan $\left(\mathrm{X}_{1}\right)$ berpengaruh terhadap loyalitas pelanggan CV Saga Selaras Pratama secara signifikan dapat diterima. Hasil penelitian ini sama dengan hasil penelitian oleh Henriawan (2015) menyatakan bahwa kualitas pelayanan berpengaruh sebesar 34,5\% terhadap loyalitas pelanggan. Hal ini membuktikan bahwa hipotesis kualitas pelayanan memiliki pengaruh terhadap loyalitas pelanggan. Dengan ini, kualitas pelayanan mempengaruhi loyalitas pelanggan CV Saga Selaras Pratama, sehingga jika kualitas layanan semakin baik, maka dapat meningkatkan loyalitas pelanggan. Dengan menunjukkan kualitas pelayanan yang baik dapat memiliki pengaruh positif terhadap loyalitas konsumen untuk terus berbelanja di CV Saga Selaras Pratama. Nilai kualitas pelayanan dengan hasil positif sebesar 0,265 berpengaruh namun memang bersifat lemah karena tidak mencapai 0,5. Hal ini menunjukkan bahwa untuk perusahaan dagang yang menjual produk, kualitas pelayanan bukan yang yang menjadi perhatian utama saat pembeli datang dan menjadi loyal pada suatu toko. Dengan komentar pada tabel 1.1 yang menyatakan beberapa hal negatif mengenai kualitas pelayanan, pembeli tetap datang untuk mendapatkan barang di Toko Saga. Untuk hal ini perlu diadakan penelitian faktor lain apa yang dapat mempengaruhi loyalitas pelanggan untuk toko yang menjual produk bersifat grosir. Nilai mean terendah sebesar 3,52 terdapat pada kemampuan pegawai dalam diberi kepercayaan misalnya dalam mengambil barang dan lain sebagainya. Para pembeli lebih merasa percaya pada pilihan produk sendiri yang bisa langsung diperiksa langsung kualitasnya.

Sedangkan untuk pengaruh kepuasan pelanggan terhadap loyalitas pelanggan, nilai signifikansi pada Uji t, dapat disimpulkan bahwa variabel kepuasan pelanggan $\left(\mathrm{X}_{2}\right)$ berpengaruh secara signifikan terhadap loyalitas pelanggan $\mathrm{CV}$ Saga Selaras Pratama, sehingga hipotesis pada penelitian ini bahwa kepuasan pelanggan $\left(\mathrm{X}_{2}\right)$ berpengaruh terhadap loyalitas pelanggan CV Saga Selaras Pratama secara signifikan dapat diterima. Hasil ini sama selaras dengan hasil yang didapatkan pada penelitian Normasari dkk (2013) serta Henriawan (2015) yang menyatakan bahwa kepuasan pelanggan berpengaruh sebesar $61,6 \%$ terhadap loyalitas pelanggan. Hal ini membuktikan bahwa hipotesis kepuasan pelanggan memiliki pengaruh terhadap loyalitas pelanggan. Dengan ini, kepuasan pelanggan mempengaruhi loyalitas pelanggan CV Saga Selaras Pratama, sehingga jika kepuasan pelanggan semakin baik, maka dapat meningkatkan loyalitas pelanggan. Dengan hasil positif sebesar 0,349 kepuasan pelanggan ini juga tergolong lemah, sama halnya dengan kualitas pelayanan. Dengan hasil positif yang tidak lebih dari 0,5 ini Toko Saga tidak dapat menurunkan perhatian untuk usaha menjaga kepuasan konsumen, sebaliknya justru semakin ditingkatkan agar para pembeli menjadi pelanggan yang loyal. Nilai mean 3,29 pada tabel 3.2 merupakan nilai yang paling rendah dan mengacu pada keinginan pelanggan untuk tidak melakukan pembelian di tempat lain. Dengan nilai paling rendah, Toko Saga yang memiliki banyak kompetitor kedepannya harus selalu menjaga kepuasan pelanggan agar tidak ditinggalkan..

\section{KESIMPULAN DAN SARAN}

\section{A. Kesimpulan}

1. Kualitas pelayanan berpengaruh positif terhadap loyalitas pelanggan karena dari hasil penelitian ini didapatkan hasil bahwa t hitung $>\mathrm{t}$ tabel dan hasil signifikansi $<$ tabel signifikansi sebesar 0,05. Dari hasil uji linier berganda didapatkan hasil positif sebesar 0,265 sehingga variabel loyalitas pelanggan akan meningkat sebesar satu satuan apabila variabel kualitas pelayanan meningkat. Dengan nilai mean terendah 3,52 pada indikator kepercayaan pada kemampuan pegawai. 
2. Kepuasan pelanggan berpengaruh positif terhadap loyalitas pelanggan karena dari hasil penelitian ini didapatkan hasil bahwa $t$ hitung $>\mathrm{t}$ tabel dan hasil signifikansi $<$ tabel signifikansi sebesar 0,05 . Dari hasil uji linier berganda didapatkan hasil positif sebesar 0,349 sehingga variabel loyalitas pelanggan akan meningkat sebesar satu satuan apabila variabel kepuasan pelanggan meningkat. Dengan nilai mean terendah 3,29 pada indikator keinginan pelanggan untuk tidak melakukan pembelian di toko lain.

3. Untuk subjek penelitian yang menggunakan toko bahan keperluan dasar yang sifatnya dibeli untuk keperluan berulang-ulang, kualitas pelayanan serta kepuasan konsumen berpengaruh tapi tidak tinggi karena bukan merupakan satu satunya pertimbangan konsumen untuk loyalitas.

\section{B. Saran}

1. Bagi CV Saga Selaras Pratama agar dapat meningkatkan kualitas pelayanan, terutama kepercayaan pegawai CV Saga Selaras Pratama dalam melayani kebutuhan pelanggannya dengan memberikan pembekalan kepada pegawai untuk memilihkan produk yang terbaik bagi pelanggan sehingga loyalitas CV saga Selaras Pratama akan meningkat.

2. Bagi CV Saga Selaras Pratama agar dapat meningkatkan kepuasan pelanggan, terutama dapat menanggapi keluhan pelanggan dengan baik dan pelanggan dapat terus melakukan pembelian di CV Saga Selaras Pratama sehingga loyalitas akan meningkat.

3. Disarankan bagi peneliti selanjutnya agar dapat memperluas penelitian dengan menggunakan faktor lain yang lebih signifikan untuk subjek penelitian berupa barang-barang dasar kebutuhan sehari-hari seperti harga, lokasi, dan lain sebagainya.

\section{DAFTAR PUSTAKA}

Agustinus, M. (2017, April 27). Ada 3,98 Juta Perusahaan Baru di RI dalam 10 Tahun Terakhir. Retrieved from Detik Finance: https://finance.detik.com/berita-ekonomi-bisnis/d-3485474/ada-398-juta-perusahaan-baru-di-ri-dalam10-tahun-terakhir

Almana, L. O., Sudarmanto, \& Ismail. (2018). Tata Kelola Perguruan TInggi Berbasis Akreditasi. Yogyakarta: Deepublish.

Aryani, D., \& Rosinta, F. (2010). Pengaruh Kualitas LAyanan Terhadap Kepuasan Pelanggan Dalam Membentuk Loyalitas Pelanggan. Jurnal Ilmu Administrasi dan Organisasi, 114-126.

Fatona, S. (2010). Kualitas Jasa Yang Mempengaruhi Loyalitas Dan Relevansinya Terhadap Kepuasan. Jurnal Dinamika Manajemen, 41-46.

Haryono, B. (2013). How to Manage Customer Voice. Yogyakarta: Andi Publisher.

Henriawan, D. (2015). Pengaruh Kualitas Pelayanan dan Kepuasan Pelanggan Terhadap Loyalitas Pelanggan. Competition, $6(2), 71-82$.

Kaihatu, T. S., Daengs, A., \& Indrianto, A. T. (2015). Manajemen Komplain. Yogyakarta: Penerbit Andi.

Karundeng, Feibe Permatasari.(2014). Kualitas Pelayanan Dan Kepuasan Pengaruhnya Terhadap Loyalitas Konsumen Pada Rumah Makan Mawar Sharron Wanea Manado. Jurnal EMBA, 639-647.

Kasmir. (2011). Etika Customer Service. Jakarta: Rajawali Press.

Kotler, P., \& Keller, K. L. (2009). Manajemen Pemasaran. Jakarta: Penerbit Erlangga.

Lovelock, C., Wirtz, J., \& Mussry, J. (2011). Pemasaran Jasa Manusia, Teknologi, Strategi. Jakarta: Penerbit Erlangga.

Normasari, S., Kumadji, S., \& Kusumawati, A. (2013). Pengaruh Kualitas Pelayanan Terhadap Kepuasan Pelanggan, Citra Perusahaan Dan Loyalitas Pelanggan. Jurnal Administrasi Bisnis, 1-9.

Putri, Y. L., \& Utomo, H. (2017). Pengaruh Kualitas Pelayanan Terhadap Loyalitas Pelanggan Dengan Kepuasan Sebagai Variabel Intervening. Among Makarti, 70-90.

Putro, S. W., Semuel, H., \& Brahmana, R. K. (2014). Pengaruh Kualitas Layanan Dan Kualitas Produk Terhadap Kepuasan Pelanggan Dan Loyalitas Konsumen Restoran Happy Garden Surabaya. Jurnal Manajemen Pemasaran, 1-9.

Sembiring, Inka Janita, Suharyono, Andriani Kusumawati. (2014). Pengaruh Kualitas Produk Dan Kualitas Pelayanan Terhadap Kepuasan Pelanggan Dalam Membentuk Loyalitas Pelanggan (Studi Pada Pelanggan Mcdonald's Mt.Haryono Malang). Jurnal Administrasi Bisnis, 1-10.

Siregar, S. (2015). Metode Penelitian Kuantitatif. Jakarta: Prenadamedia Group.

Tjiptono, F., \& Diana, A. (2015). Pelanggan Puas? Tak Cukup! Yogyakarta: Penerbit Andi. 